\title{
Long-lasting effect of obesity on skeletal muscle transcriptome
}

\author{
Ilhem Messaoudi ${ }^{1 \dagger}$, Mithila Handu ${ }^{2 \dagger}$, Maham Rais ${ }^{3}$, Suhas Sureshchandra', Byung S. Park ${ }^{4}$, Suzanne S. Fei ${ }^{5}$, \\ Hollis Wright ${ }^{5}$, Ashley E. White ${ }^{2}$, Ruhee Jain ${ }^{6}$, Judy L. Cameron ${ }^{6}$, Kerri M. Winters-Stone ${ }^{7}$ and Oleg Varlamov²
}

\begin{abstract}
Background: Reduced physical activity and increased intake of calorically-dense diets are the main risk factors for obesity, glucose intolerance, and type 2 diabetes. Chronic overnutrition and hyperglycemia can alter gene expression, contributing to long-term obesity complications. While caloric restriction can reduce obesity and glucose intolerance, it is currently unknown whether it can effectively reprogram transcriptome to a pre-obesity level. The present study addressed this question by the preliminary examination of the transcriptional dynamics in skeletal muscle after exposure to overnutrition and following caloric restriction.

Results: Six male rhesus macaques of 12-13 years of age consumed a high-fat western-style diet for 6 months and then were calorically restricted for 4 months without exercise. Skeletal muscle biopsies were subjected to longitudinal gene expression analysis using next-generation whole-genome RNA sequencing. In spite of significant weight loss and normalized insulin sensitivity, the majority of WSD-induced $(n=457)$ and WSD-suppressed $(n=47)$ genes remained significantly dysregulated after caloric restriction (FDR $\leq 0.05)$. The Metacore ${ }^{\mathrm{TM}}$ pathway analysis reveals that westernstyle diet induced the sustained activation of the transforming growth factor- $\beta$ gene network, associated with extracellular matrix remodeling, and the downregulation of genes involved in muscle structure development and nutritional processes.
\end{abstract}

Conclusions: Western-style diet, in the absence of exercise, induced skeletal muscle transcriptional programing, which persisted even after insulin resistance and glucose intolerance were completely reversed with caloric restriction.

Keywords: Insulin resistance, Caloric restriction, High-fat diet, Skeletal muscle, Obesity

\section{Background}

Caloric surplus brought about by a calorie-dense, highfat Western-style diet (WSD) is an underlying risk factor for obesity, insulin resistance (IR), and type-2 diabetes [1], with hyperglycemia and dyslipidemia playing a central role in the development of diabetic complications, including $\beta$-cell dysfunction, postprandial hyperglycemia, microvascular dysfunction, and diabetic retinopathy [2-6]. Paradoxically, many obese patients who exhibit good glycemic control through lifestyle modification or medical intervention continue to experience metabolic complications [7]. This phenomenon has been termed programming, or "metabolic memory", and

\footnotetext{
* Correspondence: varlamov@ohsu.edu

${ }^{\dagger}$ Equal contributors

${ }^{2}$ Division of Cardiometabolic Health, Oregon National Primate Research

Center, L584 505 NW 185th Ave., Beaverton, OR 97006, USA

Full list of author information is available at the end of the article
}

it has been proposed that long-lasting metabolic complications are due to sustained epigenetic modifications [8-12].

Skeletal muscle (SM) metabolic memory has been recently defined [13], but the underlying transcriptional regulation and physiological relevance are poorly understood. For example, SM metabolic memory has been demonstrated in human studies, showing that transient exposure to high-fat diet introduced sustained DNA methylation marks that were only partially erased after diet reversal [14]. One physiological function that is likely to be particularly affected by diet-induced metabolic memory is whole-body glucose disposal. SM is estimated to be responsible for up to $70 \%$ of total glucose uptake in humans, playing a major role in etiology of metabolic disease [15]. Although acute lipid infusion results in transient IR, as evidenced by an increase in inhibitory serine phosphorylation of insulin receptor 
substrate-1 (IRS1) [16, 17], chronic overnutrition can induce long-term transcriptional and physiological changes in SM. For example, high-fat diet is associated with the development of a local proinflammatory response [18, 19], activation of transforming growth factor- $\beta$ (TGF $\beta$ ) signaling [20], and the remodeling of the extracellular matrix (ECM) in SM [21-24].

One possible approach that can help reverse metabolic memory and its physiological side effects is the use of caloric restriction (CR), which is known to improve obesity outcomes in humans [25-27] and nonhuman primates (NHPs) $[28,29]$, reducing cardiovascular and metabolic disease risks after 4-6 months of intervention [25, 26, 30-32]. Hence, we conducted a preliminary study aimed at identifying differentially expressed SM genes associated with the development of WSD-induced obesity, and the extent to which short-term CR reverses gene expression.

\section{Methods}

\section{Animals and diets}

Six male rhesus macaques (Indian origin) of $12-13$ years of age were housed individually, with the cage size adjusted to animal weight according to the USDA Cage Size Guide, 8th Edition. Individual housing allowed us to mimic a sedentary lifestyle while accurately quantifying physical activity and food intake. The use of chow diet and WSD for metabolic studies in rhesus macaques has been previously described by our group and other ONPRC investigators [33-35]. Chow diet consisted of two daily meals of the Fiber-balanced Monkey Diet (15\% calories from fat, $27 \%$ from protein, and 59\% from carbohydrates; no. 5052; Lab Diet, St. Louis, MO). WSD diet consisted of two daily meals of the TAD Primate Diet (5LOP) (36\% calories from fat, $18 \%$ from protein, $45 \%$ from carbohydrates, 5A1F, Lab Diet).

Fiber-balanced Monkey Diet contains significantly lower fraction of high-glycemic carbohydrates (sucrose, fructose and lactose) and a higher proportion of low-glycemic fibers compared to TAD Primate Diet. Fiber-balanced Monkey Diet is primarily composed of non-animal products, resembling a vegetarian diet. TAD Primate Diet is closer in its composition to a calorie-rich high-fat American diet, which contains the significant proportion of saturated animal fats, cholesterol, and high-glycemic carbohydrates.

Before initiation of the study, all animals consumed ad libitum chow diet. After initiation of individual housing, animals were maintained for 2 months on ad libitum chow diet. During this period, individual baseline caloric intake was determined based on a number of consumed chow biscuits. After 2 months on chow, animals were switched to ad libitum WSD for 6 months (Table 1). The WSD was discontinued after 6 months because
HbA1c values reached prediabetic values (Table 1). Four-month caloric restriction was performed using a chow diet, with the number of chow biscuits adjusted to $70 \%$ of individual baseline caloric intake values (Fig. 1a). During each dietary intervention, animal received similar amounts of daily fruit supplements (apple or banana).

\section{Activity monitoring}

Activity was measured continuously throughout the experiment using Actical omnidirectional accelerometers (Respironics, Phoenix, AZ). Each monkey was fitted with a loose-fitting metal collar (Primate Products, Inc. Immokalee, FL) that housed the accelerometer in a snug, protective stainless steel box, as previously described [36]. Monitors were programmed to record the total number of activity counts per minute. Activity data were downloaded at least every 45 days while animals were under sedation. Total daily activity level was averaged for a 2-month baseline period, over the last week of the 6-month WSD period and over the last week of the 4-month CR period.

\section{Dual-energy X-ray absorptiometry}

Percent body fat was determined using dual-energy X-ray absorptiometry (DEXA) scanning as described [37]. Monkeys were sedated with ketamine and positioned supine on the bed of a Hologic DEXA scanner (Discovery scanner, Hologic Inc, Bedford, MA).

\section{Glucose tolerance test}

Each animal was sedated initially with Telazol (Tiletamine hydrochloride and Zolazepam hydrochloride, Fort Dodge Animal Health, Fort Dodge, IA) and subsequently with ketamine to maintain sedation. The protocol was based on that designed by Bergman et al. [38]. Dextrose $(300 \mathrm{mg} / \mathrm{kg})$ was infused intravenously through a catheter and blood samples were taken from $15 \mathrm{~min}$ before to three hours after the glucose infusion. Tolbutamide $(5 \mathrm{mg} / \mathrm{kg})$ was infused intravenously 20 min after the dextrose in order to stimulate the pancreas to secrete more insulin. All samples were immediately assayed for glucose using a YSI 2300 Stat Plus (YSI Inc., Yellow Springs, OH), and subsequently for insulin by RIA (Linco Human Insulin RIA, Millipore Corporation, Billerica, MA). Glucose and insulin were sampled at $1,3,5,10,20,40$ and $60 \mathrm{~min}$ after baseline. The sensitivity of the insulin assay was $1 \mu \mathrm{U} / \mathrm{ml}$ and the intra-assay coefficient of variation was $4.9 \%$.

\section{Cytokine, chemokine, and growth factor analysis}

Plasma samples from the following time points: before WSD, 4 months on a WSD, and 4 months on caloric restriction, (stored at $-80{ }^{\circ} \mathrm{C}$ ) were thawed and analyzed in 
Table 1 Effects of diet on physiological parameters and circulating cytokines

\begin{tabular}{|c|c|c|c|c|c|c|}
\hline Parameters & Before WSD (Chow) & After WSD & After CR & WSD vs Chow & WSD vs CR & Chow vs CR \\
\hline \multicolumn{7}{|l|}{ Appetite and activity } \\
\hline Caloric intake, \% of chow & $99.7 \pm 6.4$ & $215.4 \pm 19.1$ & ND & $p<0.01$ & ND & ND \\
\hline Activity (count/day) & $28624.7 \pm 6842.7$ & $33545.2 \pm 5650.0$ & $26284.0 \pm 6794.2$ & NS & NS & NS \\
\hline \multicolumn{7}{|l|}{ Body composition } \\
\hline Weight (kg) & $11.5 \pm 0.6$ & $15.1 \pm 1.1$ & $12.5 \pm 1.1$ & $p<0.01$ & $p<0.01$ & NS \\
\hline Body fat (g) & $2040.3 \pm 357.0$ & $5855.4 \pm 881.0$ & $3934.2 \pm 820.7$ & $p<0.01$ & $p<0.001$ & $p<0.05$ \\
\hline Lean mass (g) & $9028.2 \pm 354.9$ & $8793.9 \pm 437.7$ & $8179.4 \pm 443.6$ & NS & NS & $p<0.01$ \\
\hline \multicolumn{7}{|l|}{ Glucose homeostasis } \\
\hline AUC glucose (mg/dl) & $6823.1 \pm 440.0$ & $8751.5 \pm 718.5$ & $6735.3 \pm 538.5$ & $p<0.05$ & $p<0.05$ & NS \\
\hline AUC insulin (mg/dl) & $4750 \pm 647.2$ & $10404 \pm 2078.9$ & $7273.6 \pm 1869.3$ & $p<0.05$ & $p<0.05$ & NS \\
\hline Fasting glucose (mg/dl) & $63.5 \pm 7.2$ & $63.6 \pm 4.0$ & $65.5 \pm 2.8$ & NS & NS & NS \\
\hline Fasting insulin (mg/dl) & $21.5 \pm 7.8$ & $58.5 \pm 12.2$ & $29.5 \pm 6.6$ & $p<0.01$ & $p<0.05$ & $p<0.05$ \\
\hline HbA1c, percent & $6.02 \pm 0.15$ & $6.92 \pm 0.23$ & $6.35 \pm 0.19$ & $p<0.001$ & $p<0.05$ & NS \\
\hline HOMA-IR & $4.05 \pm 1.86$ & $9.7 \pm 2.55$ & $4.9 \pm 1.3$ & $p<0.01$ & $p<0.05$ & NS \\
\hline \multicolumn{7}{|l|}{ Serum cytokines } \\
\hline IL6, \% of chow & $100 \pm 0.0$ & $68.9 \pm 10.0$ & $120.2 \pm 7.7$ & NS & $p<0.01$ & NS \\
\hline IL-8, \% of chow & $100 \pm 0.0$ & $73.5 \pm 13.2$ & $59.6 \pm 11.6$ & $p<0.001$ & NS & $p<0.001$ \\
\hline Eotaxin, \% of chow & $100 \pm 0.0$ & $60.7 \pm 6.9$ & $49.5 \pm 3.6$ & $p<0.001$ & NS & $p<0.001$ \\
\hline MIF Analyte, $\%$ of chow & $100 \pm 0.0$ & $212.8 \pm 64.4$ & $472.9 \pm 110.2$ & NS & $p<0.05$ & $p<0.01$ \\
\hline $\mathrm{PAl}-1, \mathrm{ng} / \mathrm{ml}$ & $104.2 \pm 5.08$ & $121.2 \pm 4.73$ & $125.2 \pm 5.33$ & $p<0.05$ & NS & $p<0.01$ \\
\hline
\end{tabular}

Following 2 months on ad libitum chow diet, animals were provided with ad libitum access to a WSD for 6 months, and then switched back to chow, while being calorically restricted to $70 \%$ of individual baseline values. Body composition and glucose homeostasis were assessed before WSD (Chow), 6 months after WSD, and 4 months after CR. Serum cytokine and PAI-1 levels were determined before WSD, 4 months after WSD, and 4 months after CR. Daily caloric intake was determined during chow and WSD periods. Daily caloric intake and serum cytokine levels are presented as normalized a percent of baseline values. Values are Means \pm SEM, $n=6$. Statistical significance was determined using repeated-measure one-way ANOVA. ND not determined, NS not significant

duplicates using the Invitrogen Cytokine Monkey Magnetic 29-Plex Panel per the manufacturer's instructions, using the Magpix spectrophotometer (Life Technologies, Grand Island, NY). The panel includes monocyte chemoattractant protein 1 (MCP-1; CCL2), fibroblast growth factor basic (FGF- $\beta$ ), IL-1 $\beta$, granulocyte colonystimulating factor (G-CSF), IL-10, IL-6, IL-12, RANTES, eotaxin, IL-17, macrophage inflammatory protein 1 alpha (MIP-1 $\alpha)$, granulocyte-macrophage colonystimulating factor (GM-CSF), macrophage inflammatory protein 1 beta (MIP-1 $\beta$ ), IL-15, epidermal growth factor (EGF), IL-5, hepatocyte growth factor (HGF), vascular endothelial growth factor (VEGF), IFN- $\gamma$, monocytederived chemokine (MDC; CCL22), interferon-inducible T cell alpha chemoattractant (ITAC; CXCL11), migration inhibition factor (MIF), IL-1 receptor agonist (IL-1RA), TNF- $\alpha$, IL-2, IFN-gamma-inducible protein 10 (IP-10, CXCL10) monokine induced by IFN-gamma (MIG; CXCL9), IL-4, and IL-8 (see Additional file 1: Figure S1 for details).

\section{Muscle biopsies}

Soleus muscle are primarily comprised of slow twitch fibers [39] and has a greater sensitivity to insulin compared to fast twitch muscles [40]. Soleus muscle displays a well-documented response to obesity, as demonstrated in human [41, 42] and rhesus macaque [43] studies, representing an appropriate translational model for studying the effects of diet on SM physiology. SM biopsies were performed by expert surgical personnel at ONPRC according to well-accepted veterinary surgical procedures under sterile conditions and appropriate anesthesia with postoperative pain control. Food was withheld for approximately $12 \mathrm{~h}$ prior to the procedure. Animals were sedated with $100 \mathrm{mg}$ ketamine combined with $0.1 \mathrm{mg}$ Glycopyrrolate administered intramuscularly. Once the intravenous catheter was placed, animals received $0.5 \mathrm{mg}$ Hydromorphone- $\mathrm{HCl}$ intravenously. Animals were endotracheally intubated with an endotracheal tube (size 4.0-6.0) and general anesthesia was induced with $3 \%$ Isoflurane for $2-3 \mathrm{~min}$. Inhalant anesthesia was maintained at $1-2 \%$ Isoflurane. Inhalant anesthetics was combined with $100 \%$ oxygen administered at a rate of $1-1.5 \mathrm{~L} / \mathrm{min}$.

A 2-cm incision was made lateral to the soleus muscle. Using sharp dissection, an approximately $1 \times 0.5 \mathrm{~cm}$ muscle specimen from the lateral aspect of soleus muscle was obtained, rinsed in saline, and snap-frozen 


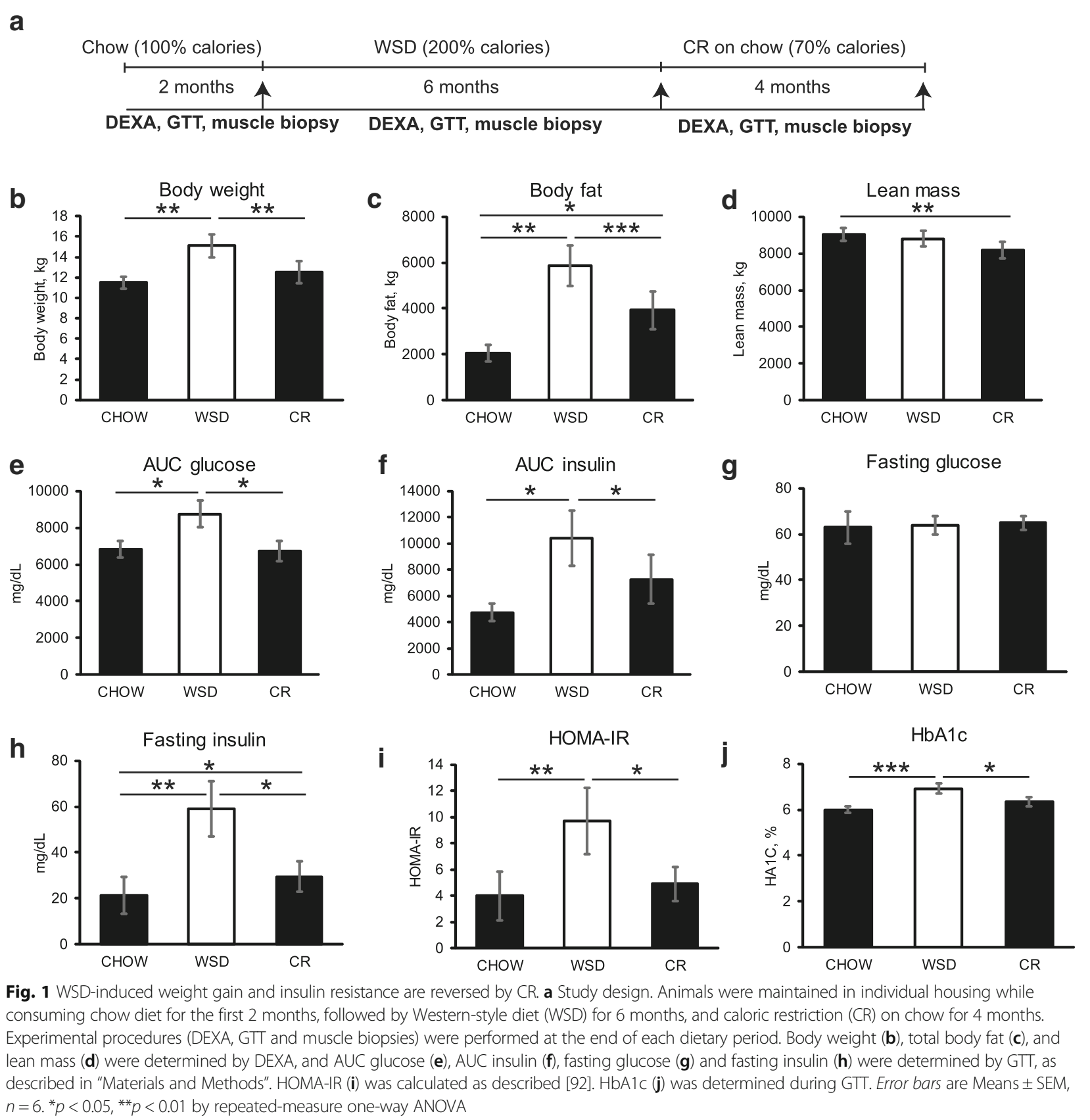

in liquid nitrogen. This surgical procedure produced minimal amount of bleeding at the site of biopsy. Closure of the muscle fascia with simple continuous 4-0 Monocryl was followed by continuous intradermal 4-0 Monocryl in the skin. Recovery was on the OR table until extubation. Additional heat and oxygen support was provided as needed during the recovery period. Post-operative analgesia was provided for $48-72 \mathrm{~h}$ following the surgical procedure, using Hydromorphone $\mathrm{HCl} \quad(0.05-0.4 \mathrm{mg} / \mathrm{kg}$, administered intramuscularly, three times a day), and buprenorphine $(0.01-0.1 \mathrm{mg} / \mathrm{kg}$, administered intramuscularly, once a day). The standard 48 to 72 -h opioid protocol for post-operative analgesia was used. Post-operative monitoring and assessment of pain and distress were accomplished by surgical veterinary staff for a minimum of 7 days.

\section{RNA isolation}

Frozen 100-mg muscle specimens were homogenized by shaking ( $25 \mathrm{rps}$ for $2 \mathrm{~min}$ ) in 2 -ml extraction tubes supplied with a $5-\mathrm{mm}$ pre-chilled metal bead (McMaster-Carr, Elmhurst, IL) and $1 \mathrm{ml}$ of ice-cold 
TriReagent (MRC Inc., Cincinnati, OH), using a TissueLyser II (Qiagen, Hilden, Germany). One hundred microliters bromochloropropane (MRC Inc., Cincinnati, $\mathrm{OH}$ ) were added to each tissue sample, to enhance phase separation, and incubated at room temperature for $5 \mathrm{~min}$. Samples were mixed and centrifuged at $12,000 \times g$ for $15 \mathrm{~min}$ at $4{ }^{\circ} \mathrm{C}$. The RNA-containing upper aqueous phase was transferred to a new tube and mixed with $12 \mu \mathrm{l}$ glycogen (Thermo Fisher Scientific, Waltham, MA) and $0.5 \mathrm{ml}$ isopropanol. Tubes were centrifuged at $15,000 \times g$ for $10 \mathrm{~min}$ at $25{ }^{\circ} \mathrm{C}$, pellets were washed twice with 0.7 $\mathrm{ml} 75$ and $100 \%$ ethanol, air-dried at room temperature for 10-15 min, and resuspended in 10 $\mathrm{mM}$ Tris- $\mathrm{HCl}, \mathrm{pH}$ 8.0. RNA concentration and purity were determined using NanoDrop ND1000 (Thermo Fisher Scientific). The average A260/280 value of purified RNA samples was 2.04 .

\section{RNAseq analysis}

RNAseq libraries (3 longitudinal time points/3 animals) were prepared using the TruSeq protocol (Illumina, San Diego, CA). Briefly, poly (A) + RNA was purified using oligo-dT coated magnetic beads, chemically fragmented followed by cDNA generation using random hexamer primers. The cDNAs ends were repaired and ligated to library adaptors. Following clean-up with AMPure XP beads (Beckman Coulter Inc., Brea, CA), the libraries were amplified using 11 PCR cycles. The amplified libraries were cleaned using AMPure XP beads. The library was profiled on a Bioanalyzer (Agilent, Santa Clara, CA) and quantified using qRT-PCR (Kapa Biosystems, Wilmington, MA) on a StepOnePlus qRTPCR workstation (Life Technologies, Carlsbad, CA). Libraries were mixed for multiplexing and the final concentration of the mix was determined by qRT-PCR. The mix was diluted to $1 \mathrm{nM}$ for denaturation and then diluted to deliver optimal clustering on the flow cell. Flow cells were prepared on a cBot (Illumina, San Diego, CA). Libraries were sequenced on a HiSeq 2000 (Illumina, San Diego, CA). Data was assembled into standard fastq files using Bcl2Fastq (Illumina, San Diego, CA).

\section{Bioinformatic analysis}

Bioinformatic analysis was carried out as described [44]. The quality of the raw reads was verified using FastQC (version 0.11.3). Low quality bases as well as any remaining Illumina adapters were trimmed. Reads with less than 25 bases remaining were discarded. The remaining reads were aligned to the rhesus macaque genome (Macaca mulatta 1.0) from ENSEMBL using splice aware short read aligner suite Bowtie2/TopHat2 (REF1) in a strand-specific fashion allowing up to 5\% mismatches. The transcript counts per gene were calculated using SummarizeOverlaps function (Union method) in GenomicRanges (REF2) package in R. Transcripts were normalized using trimmed mean of $M$ values (TMM) method followed by differential gene expression analysis using edgeR (REF3) resulting in candidate differentially expressed genes (DEGs), with fold change $(F C) \geq 2$ and a false discovery rate $(F D R) \leq 0.05$. Functional enrichment was done using MetaCore

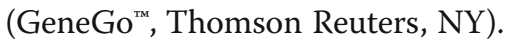

\section{Quantitative RT-PCR (qRT-PCR) analysis of gene expression}

Two micrograms of mRNA samples were used for cDNA synthesis using the SuperScript VILO $^{\mathrm{TM}}$ cDNA Synthesis kit (Thermo Fisher Scientific). cDNA was diluted 1:10 and $1 \mu \mathrm{l}$ was used in $10 \mu \mathrm{l}$ of qRT-PCR reactions using the Power SYBR Green Master mix (Thermo Fisher Scientific), according to manufacturer's instructions. qRT-PCR was performed using an ABI7900 thermocycler (Applied Biosystems, Inc). Primer sequences are shown in Additional file 2: Table S4. The data were normalized to the RPL13A housekeeping gene and the fold change was calculated using $2^{\wedge}$-ddCT method.

\section{Statistical analysis}

All data was checked for normality and homogeneity of variance. If necessary, data was transformed using log or square root transformations to meet criteria for parametric tests. Comparisons between the baseline time period and WSD and CR periods were made using repeated measure one-way ANOVA, with a Bonferroni correction for multiple comparisons. Data are presented as mean \pm standard error of the mean (SEM). All statistical analyses were conducted using the SPSS software package, version 23.0 (SPSS Inc., Chicago, Illinois).

\section{Results \\ Diet effects on physiological parameters}

Over the course of the WSD, the total caloric intake increased significantly compared to the chow period. In contrast, total physical activity levels were not significantly affected either by a WSD or CR (Table 1 and Fig. 1a). Body weight and fat mass increased significantly following consumption of the WSD. Although fat mass decreased significantly following $\mathrm{CR}$, it did not return to baseline levels. In contrast, lean mass was not affected by the WSD, but decreased significantly after CR compared to the chow period (Table 1 and Fig. $1 \mathrm{~b}-\mathrm{d}$ ).

WSD induced glucose intolerance and IR as evidenced by an increase in area under the curve (AUC) glucose and AUC insulin values during glucose tolerance tests (GTTs), as well as HOMA-IR and HbA1c levels (Table 1 and Fig. 1e, f, i and j). CR significantly decreased these parameters, suggesting a return to normal glucose 
tolerance and improved insulin sensitivity following weight loss. Fasting insulin, but not fasting glucose, increased significantly following WSD, and then decreased after CR, albeit remaining significantly elevated compared to the chow period (Table 1 and Fig. $1 \mathrm{~g}$ and h). Collectively, CR restored normal glucose tolerance and insulin sensitivity to its normal level while having only a partial effect on fat loss in rhesus macaques exposed to a WSD.

\section{Diet effects on circulating cytokines}

Circulating levels of interleukin-6 (IL-6) were not significantly affected by WSD, but increased significantly after CR. Circulating IL-8 levels were decreased after WSD and remained significantly reduced after short-term CR. Similarly, serum concentrations of eotaxin (CCL11) decreased significantly after a WSD and remained low during CR. In contrast, serum concentrations of macrophage migration inhibitory factor (MIF) almost doubled after WSD and then quadrupled after short-term CR (Table 1). Circulating levels of plasminogen activator inhibitor 1 (PAI-1) were elevated by WSD and remained elevated after CR (Table 1). The Luminex analysis of 29 circulating cytokines, chemokines and growth factors is shown in Additional file 1: Figure S1.

\section{Diet effects on skeletal muscle gene expression WSD induces sustained transcriptional changes that largely persist after $C R$}

To study diet-induced changes in the SM transcriptome, soleus muscle biopsies were collected longitudinally, before and after exposure to the WSD and following CR, and then subjected to RNAseq gene expression analysis. Differentially expressed genes (DEGs) were identified using three comparisons: WSD/CHOW, CR/WSD, and CR/CHOW (Fig. 2). This experimental design allowed us to identify DEGs whose expression reversed or remained a

\section{CHOW}

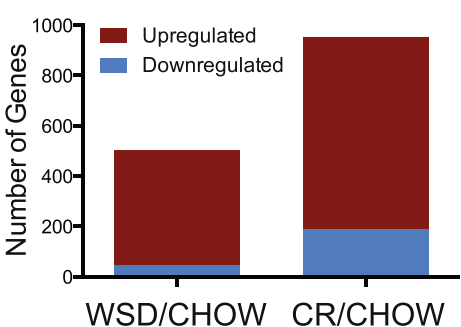

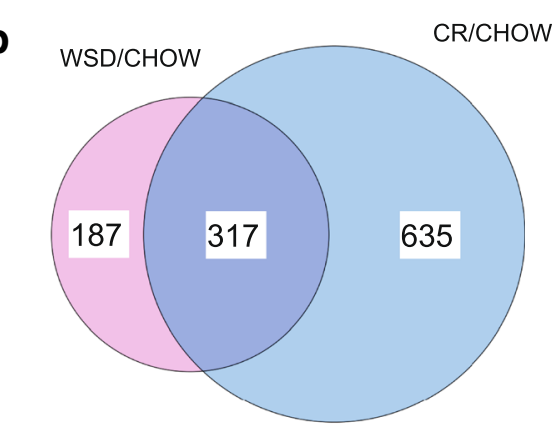

e

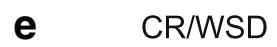

C

$$
\text { d }
$$

$\mathrm{CR} / \mathrm{CHOW}$

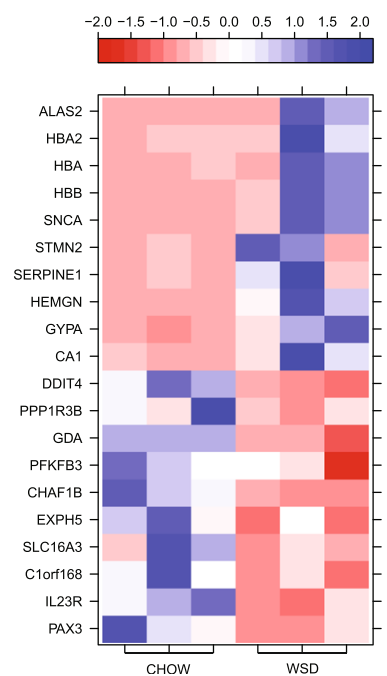

$-2.0-1.5-1.0-0.5 \quad 0.0 \quad 0.5 \quad 1.0 \quad 1.5 \quad 2.0$

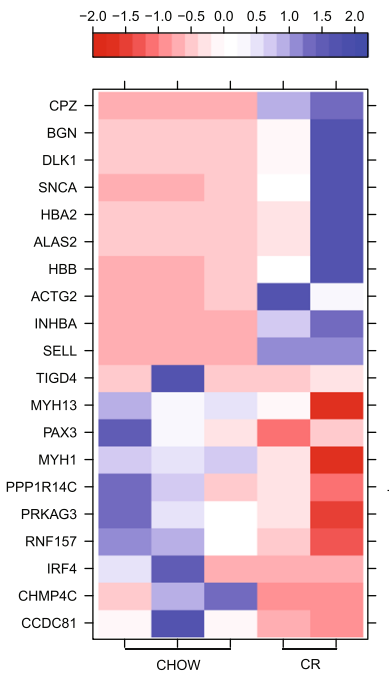

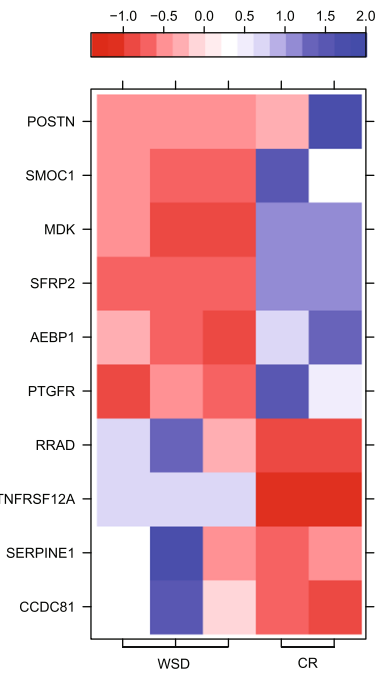

Fig. 2 WSD induces sustained alterations in skeletal muscle transcription. Soleus muscle biopsies were collected longitudinally, before and after exposure to the WSD and after CR, and then subjected to RNAseq gene expression analysis, as described in "Materials and Methods". DEGs were identified using three independent comparisons: a-c WSD vs chow (WSD/CHOW); e CR vS WSD (CR/WSD); and $\mathbf{a}, \mathbf{b}$ and $\mathbf{d}$ CR vs Chow (CR/CHOW). a The number of upregulated (brown) and downregulated (blue) genes from WSD/CHOW and CR/CHOW categories in rhesus macaque genome. b Venn diagram shows an overlap between WSD/CHOW and CR/CHOW genes. Heat maps of top DEGs during the transition from chow to WSD (c), CR vs chow (d), and CR vs. WSD (e) Each column represents an individual animal 
resistant to CR. More than $90 \%$ of WSD/CHOW DEGs were upregulated (total gene count: $D_{\text {EG }}=457$; $\mathrm{DEG}_{\text {down }}=47$; Additional file 2: Table S1 and Fig. 2a). Similarly, $80 \%$ of $C R / C H O W$ DEGs were also upregulated (total gene count: $\mathrm{DEG}_{\text {up }}=761, \mathrm{DEG}_{\text {down }}=191$; Additional file 2: Table S2 and Fig. 2a). Many DEGs identified in the present study are found to be expressed in human erythroid cells [45] (erythroid gene count: $W S D / C H O W D_{\text {DE }}=244, \mathrm{DEG}_{\text {down }}=15$; $C R / C H O W \mathrm{DEG}_{\text {up }}=375, \mathrm{DEG}_{\text {down }}=67$; Additional file 2: Table S3). This analysis suggests that red blood cells residing in the intramuscular capillary system may contribute to SM gene expression, or alternatively, some of these genes are expressed both in SM and erythroid cells.

\section{Only a small subset WSD-affected DEGs shows reversible regulation by $C R$}

There were 317 genes whose expression was significantly affected by a WSD and remained dysregulated after CR (Fig. 2b). Moreover, only $10 \mathrm{CR} / \mathrm{WSD}$ DEGs were identified in the present study (Fig. 2e and Table 2), suggesting that only few of the WSD-induced and WSD-suppressed genes are reversed by CR. Some of the notable genes in the CR/WSD list included SERPINE1, whose expression was initially upregulated by a WSD, and then reversed by $C R$. Other reversed genes included Ras-related associated with diabetes $(R R A D)$ and the tumor necrosis factor receptor superfamily-12A (TNFRS12A) (Fig. 2e and Table 2).

\section{The most upregulated and most downregulated genes affected by diet}

Genes that were highly upregulated by the WSD encoded the heme biosynthesis enzyme 5 '-aminolevulinate synthase 2 (ALAS2), several isoforms of hemoglobin
$(H B A 2, H B A, H B B)$, the regulator of hematopoietic cell proliferation hemogen (HEMGN), and the erythrocyte sialoglycoprotein glycophorin A (GYPA) (Fig. 2c and Additional file 2: Table S1). WSD induced the downregulation of several metabolic genes, encoding glycolytic enzymes 6-phosphofructo-2-kinase/fructose-2,6-bisphosphatase- 3 and 1 (PFKFB3 and 1), the glycogen synthesis regulatory gene, protein phosphatase 1 , regulatory subunit $3 \mathrm{~B}(P P P 1 R 3 B)$, uncoupling protein $3(U C P 3)$ and the negative regulator of $\mathrm{mTORC}$, DNA-damageinducible transcript 4 (DDIT4) (Fig. 2c and Additional file 2: Table S1). The most upregulated genes in the CR/ CHOW comparison were related to ECM remodeling, including metallopeptidase carboxypeptidase $\mathrm{Z}(C P Z)$, biglycan $(B G N)$, selectin $\mathrm{L}(S E L L)$ and several types of collagen. The most downregulated genes in the CR/ $\mathrm{CHOW}$ group included tiger transposable element derived 4 (TIGD4), the developmental transcription factor $P A X 3$, myosin heavy chain 1 and 13 (MYH1 and $M Y H 13)$, and interferon regulatory factor 4 (IRF4, Fig. 2d and Additional file 2: Table S2).

\section{TGF $\beta$ pathway and adhesion molecule genes remain upregulated after $C R$}

We identified 317 genes whose expression was significantly affected by a WSD but not reversed by CR (Fig. 2b). Functional enrichment was performed using Metacore $^{\mathrm{Tm}}$ and showed that these DEGs enriched to gene ontology (GO) terms associated with ECM organization and cell adhesion (Fig. $3 \mathrm{a}-\mathrm{c}$ ). The former included multiple isoforms of collagens, such as COL4A1, COL5A2, COL6A2, COL6A3, COL12A1, and COL14A1, the ECM remodeling metalloproteases ADAMTS2, and matrix metalloprotease MMP2 (Fig. 3b). Adhesion molecule genes included laminin LAMA4 gene, cadherin-like gene FAT1, and thrombosponin-5

Table 2 The effect of CR on WSD-induced gene expression

\begin{tabular}{|c|c|c|c|c|}
\hline Gene symbol & Description & Log_FC & $P$-Value & FDR \\
\hline POSTN & Periostin, osteoblast specific factor & 3.18 & $1.46 \mathrm{E}-06$ & 0.0025 \\
\hline SMOC1 & SPARC related modular calcium binding 1 & 1.97 & 1.30E-07 & 0.0005 \\
\hline MDK & Midkine (neurite growth-promoting factor 2) & 1.82 & $1.11 \mathrm{E}-05$ & 0.02 \\
\hline SFRP2 & Secreted frizzled-related protein 2 & 1.48 & 2.80E-07 & 0.0006 \\
\hline AEBP1 & AE binding protein 1 & 1.41 & $1.00 \mathrm{E}-06$ & 0.002 \\
\hline PTGFR & Prostaglandin F receptor & 1.31 & $2.72 \mathrm{E}-05$ & 0.03 \\
\hline RRAD & Ras-related associated with diabetes & -1.57 & $1.61 \mathrm{E}-07$ & 0.0005 \\
\hline TNFRSF12A & Tumor necrosis factor receptor superfamily $12 \mathrm{~A}$ & -1.71 & $8.20 \mathrm{E}-08$ & 0.0005 \\
\hline SERPINE1 & Serpin peptidase inhibitor, clade $\mathrm{E}$ & -2.53 & $2.20 \mathrm{E}-05$ & 0.03 \\
\hline CCDC81 & Soiled-coil domain containing 81 & -2.68 & 2.43E-08 & 0.0003 \\
\hline
\end{tabular}

Soleus muscle biopsies were collected longitudinally, before WSD, 6 months after WSD, and 4 months after CR. Tissue samples were subjected to RNA extraction and RNAseq gene expression and bioinformatic analysis as described in "Materials and Methods". Table shows upregulated and downregulated differentially expressed genes (DEGs) after CR in comparison with WSD (CR/WSD). Bioinformatic analysis was performed using FDR $\leq 0.05$. Log_FC (fold change) was calculated as $\log (F C, 2)$ 


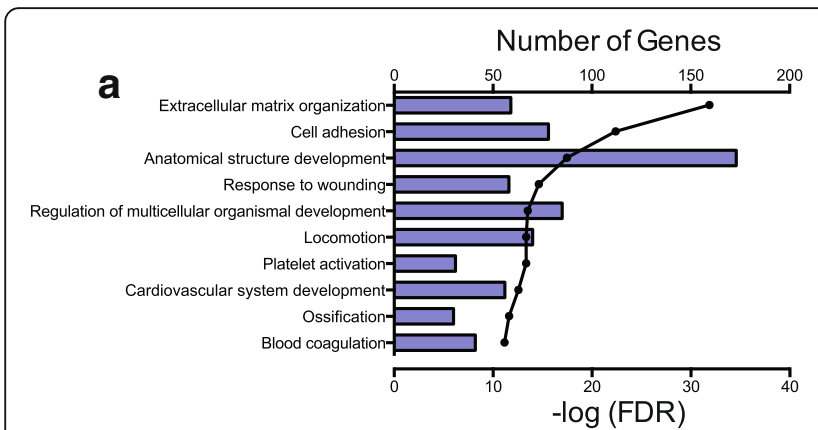

b Extra-cellular matrix

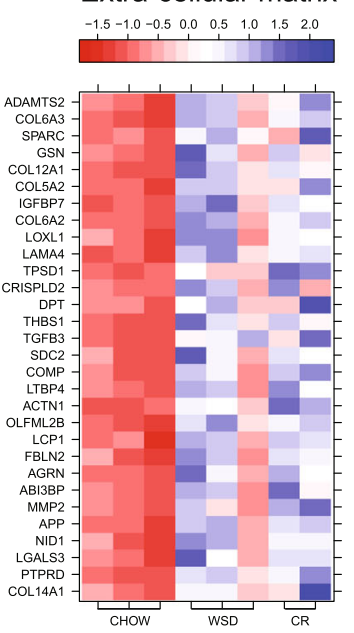

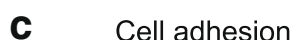

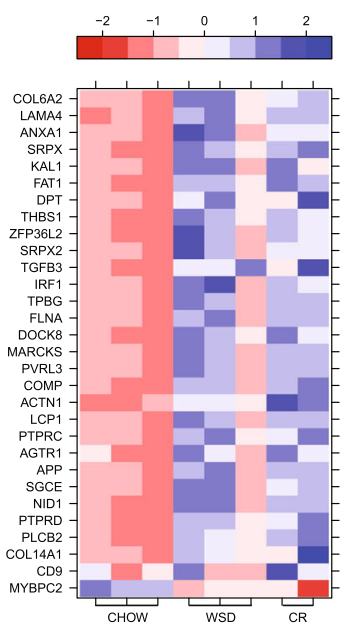

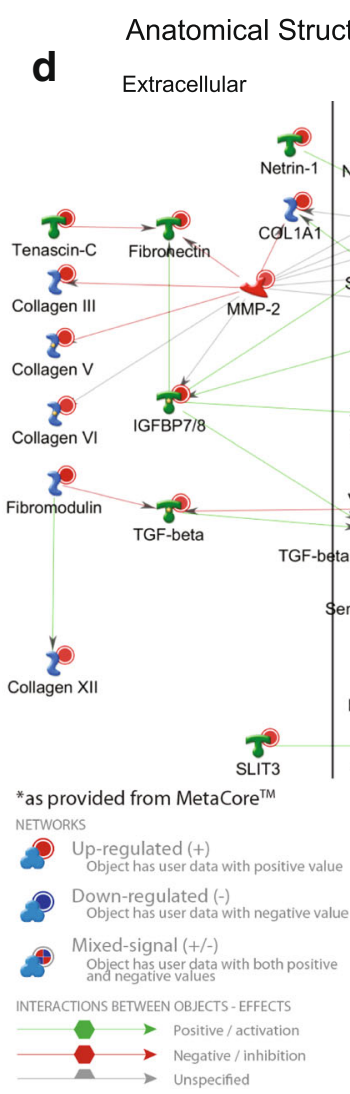

Cytoplasm Nucleus

Fig. 3 TGF $\beta$ pathway genes remain upregulated after CR. a Functional enrichment of DEGs with the highest FDR values common for WSD/CHOW and CR/CHOW categories. Heat maps of top DEGs involved in ECM organization (b) and cell adhesion (c). Each column represents an individual animal. d Anatomical structure development common gene network indicates upregulated (red) and downregulated (blue) DEGs. Positive and negative interactions between genes are represented by green and red arrows, respectively. Cellular compartmentalization of gene products is indicated

gene COMP (Fig. 3c). The network analysis of DEGs that map to the GO term "anatomical structure development" and are known to directly interact show that genes encoding several members of the TGF $\beta$ - signaling pathway remains upregulated after the diet switch to CR (Fig. 3d).

\section{Muscle development genes affected by caloric restriction}

We detected 635 differentially expressed $\mathrm{CR} / \mathrm{CHOW}$ genes that were enriched to GO terms associated with muscle development (Fig. 4a). Among the downregulated muscle development genes were the winglesstype MMTV integration site family, member 9A (WNT9A) involved in the neuromuscular junction formation [46], the transcription factor SOX6 whose deficiency is associated with an increased number of slow myofibers and a decreased number of fast myofibers [47], and nitric oxide synthase (NOS1), a positive regulator of SM hypertrophy [48] (Fig. 4b). Several other downregulated genes important for muscle development include BIN1/M-Amphiphysin2 (BIN1), which is frequently mutated in centronuclear myopathies [49], and muscle-restricted coiled-coil $(M U R C)$ playing the pivotal role in skeletal myogenic differentiation [50] (Fig. 4b-d). Thus, downregulation of these genes may collectively account for muscle loss after CR (Fig. 1d and Table 1).

\section{Energy metabolism and other genes affected by caloric restriction}

Additional analysis using disease terms revealed enrichment to nutritional processes (Fig. 4c). Some of the downregulated DEGs that mapped to these disease pathways include IRS1, fructose-1,6-bisphosphatase 2 (FBP2) and PRKAA2 genes (Fig. 4c). Other diseaserelated genes that were upregulated by $C R$ were the diabetes-related ankyrin repeat protein (ANKRD23), whose expression in SM is increased under diabetic conditions [51] and the growth arrest-specific 6 (GAS6) gene, which is strongly associated with adiposity, inflammation, and insulin resistance status among overweight people [52] (Fig. 4c). Interestingly, the 


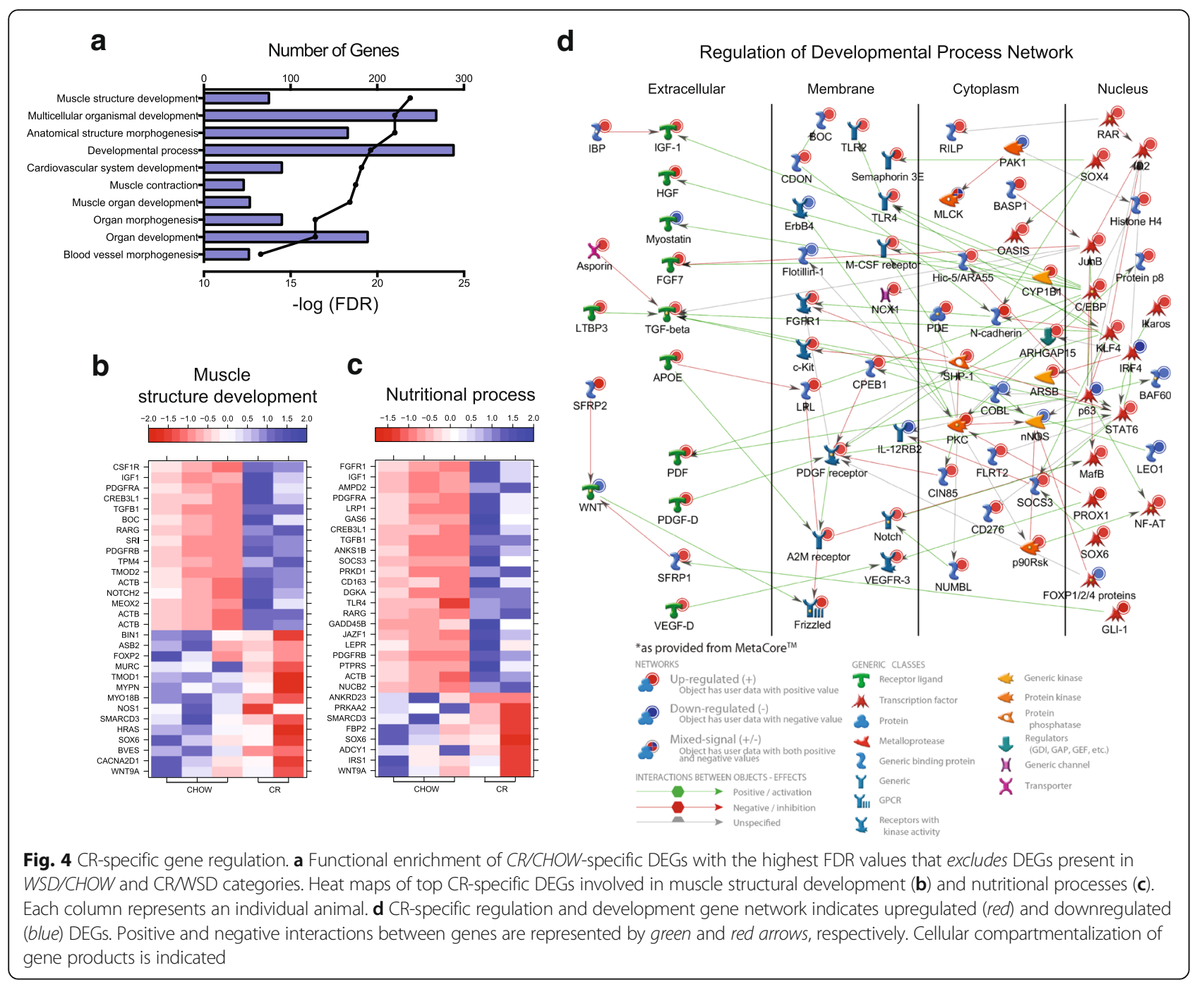

expression of several inflammatory genes such as Tolllike receptor 4 (TLR4), CD163, and TGFB1 increased following CR (Fig. 4c and d). A network of DEGs that mapped to the GO term "developmental process" (Fig. 4d) is consistent with the sustained activation of the TGF- $\beta$ network after CR. The possible mechanism of its activation may involve the positive action of the cytokine-induced STAT6 transcriptional factor, which was also upregulated during $\mathrm{CR}$, and the suppressor of cytokine signaling 3 (SOCS3), which controls macrophage polarization (Fig. 4d). Using qRT-PCR, we confirmed that energy metabolism-related genes, including IRS1, PRKAG3, PFKM, UCP3, PFKFB1 and $P R K A A$ were significantly downregulated or showed a trend toward downregulation by WSD and CR (Fig. 5). In contrast, the gene of collagen-4a (COL4A) showed the opposite regulation by WSD and CR. Interestingly, the SET domain-containing lysine methyltransferase 7 (SETD7) was significantly downregulated after CR (Fig. 5).

\section{Discussion}

\section{Transcriptional remodeling of ECM}

The present study demonstrates that WSD induced SM transcriptional reprograming that remained persistent even after obesity and glucose intolerance were reversed by CR. Remarkably, 457 WSD-induced and 47 WSDsuppressed genes were not readily reversed by $C R$ and remained upregulated or downregulated, respectively. Upregulated genes detected by our RNAseq analysis encoded ECM-related proteins, including collagens (COL1A1, COL3A1, COL4A1, COL5A1, COL5A2, COL6A1, COL6A2, COL6A3, COL8A2, COL11A1, COL12A1, COL14A1 and COL21A1), integrins (ITGBL1, ITGA4 and ITGA5), and matrix metalloproteases (MMP2 and MMP25; Additional file 2: Table S1). This finding is consistent with recent human studies, demonstrating the upregulation of COL1, COL3 and MMP2 in response to overfeeding [53]. It has been suggested that ECM remodeling is associated with the development of diet-induced IR, contributing to the pathophysiology of 


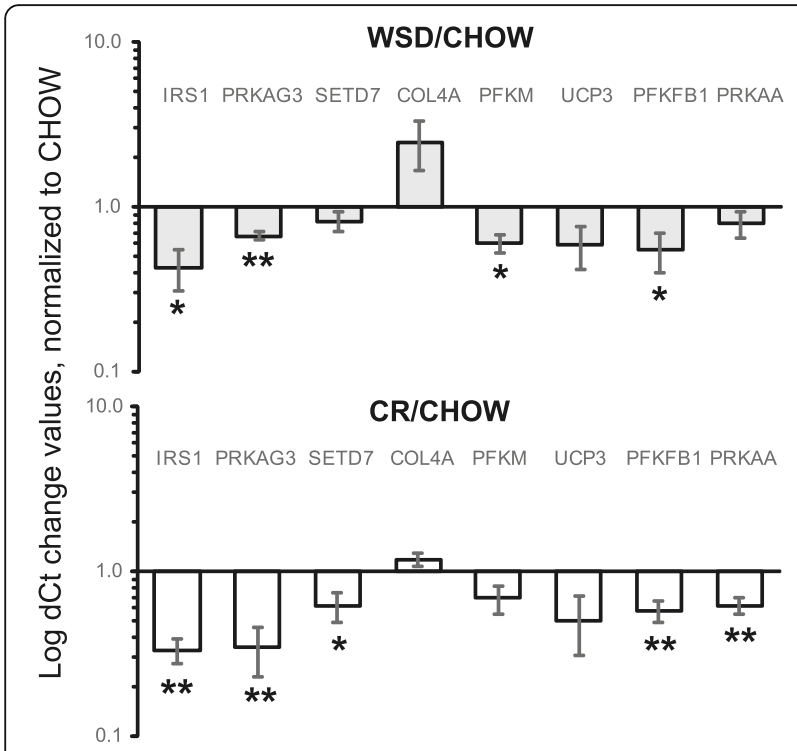

Fig. 5 qRT-PCR validation of RNAseq analysis of gene expression. Changes in SM mRNA levels were determined as described in "Materials and Methods". Graphs represent logarithm mean fold changes for WSD Ct values normalized to CHOW (filled bars) and CR Ct values normalized to CHOW (open bars). Error bars are Means \pm SEM, $n=5 .{ }^{*} p<0.05,{ }^{* *} p<0.01$ by repeated-measure one-way ANOVA

type 2 diabetes [24]. The importance of ECM-integrin interactions in the development of IR has been demonstrated in mice lacking integrin-alpha ${ }_{2}$ beta $_{1}$ (itga2 (-/-)), as evidenced by the fact that high-fat feeding induced COL3 and COL4 gene expression in SM of transgenic mice, while insulin sensitivity was increased [23]. Consequent studies revealed that the deletion of MMP9, the primary enzyme that mediates the degradation of COL4 prevented the development of diet-induced IR [54].

\section{Relevance to metabolic memory}

Because a subset of ECM genes remained dysregulated following CR, we suspected the involvement of epigenetic modifiers in transcriptional regulation. One such modifier SETD7 was significantly downregulated following CR. SETD7 has been previously implicated in hyperglycemia-induced epigenetic activation of profibrotic genes related to nephropathies and vascular complications (TGF $\beta$, SERPINE1, COL1A, and MCP-1), being involved in metabolic memory [9]. Metabolic memory in humans has been documented in the Diabetes Control and Complications Trial (DCCT) and the Epidemiology of Diabetes Interventions and Complications (EDIC) study [55-57]. Animal studies demonstrated that metabolic memory is responsible for sustained transcriptional changes in fibrotic and inflammatory genes that are involved in diabetic complications in smooth muscle cells [58, 59]. Consistent with the idea of metabolic memory, studies in humans showed that high-fat diet can induce long-lasting DNA methylation marks in proinflammatory genes that are not easily removed with diet reversal [14], although the functional significance of these changes remains to be determined.

\section{Physiological significance of SM programing}

One possible implication of SM metabolic memory is a higher susceptibility of obesity-exposed individuals to IR and muscle loss, as a result of sustain diet-induced alterations in local gene expression. There is evidence suggesting that IR and obesity are associated with a decrease in the proportion of slow twitch fibers [60], representing the majority of soleus muscle [39], while leanness is associated with increased oxidative capacity of SM [61]. Although the present study did not directly address the effects of WSD and CR on fiber composition and metabolic properties of SM, the RNAseq analysis suggests that WSD induced the sustained downregulation of insulin signaling (IRS1), glycolytic (PFKM, PFKFB1), and mitochondrial (UCP3) genes and that this effect persisted after obesity was reversed with CR (Fig. 5). Interestingly, the slow twitch-specific myosin heavy chain isoform $M Y H 1$ was also downregulated after CR (Fig. 2d). It is possible that sustained transcriptional changes observed in the present report correlate metabolic dysfunction, although this hypothesis needs further verification using functional studies.

\section{Transcriptional response of immunological genes}

SM and systemic inflammation may play a role in the development of long-term obesity complications. Our RNAseq analysis showed that WSD induced the significant upregulation of mRNA encoding CCL2, which persisted after the animals were switched to CR. The upregulation of CCL2 and a concomitant increase in proinflammatory macrophages has been recently reported in quadriceps of mice fed high-fat diet for 1 week [62]. Furthermore, both CD163 and TLR4 were also upregulated following CR. CD163 is exclusively expressed in monocytes and macrophages [63] to regulate the clearance and endocytosis of hemoglobin and haptoglobin complexes by macrophages, and may thereby protect tissues from free hemoglobin-mediated oxidative damage [64]. These results are in line with previous studies that reported activation of inflammatory pathways in SM following obesity and high-fat diet [65]. As described in this manuscript, an increase in macrophage markers was observed in SM of obese nondiabetic patients [66] and in SM of mice fed high-fat diet for 3 weeks [67]. The development of obesity involves the recruitment of inflammatory CD11C+ macrophages to SM [62]. Interestingly, exposure to palmitate induces a release 
of IL-6 and CCL2 from macrophages [66], while conditional media from palmitate-treated macrophages sufficed to induce IR in cultured myotubes $[68,69]$.

\section{Changes in circulating cytokines}

TNFa: We did not observe a systemic proinflammatory response and serum cytokines TNF $\alpha$ and IL-1 were not significantly affected by diet (Additional file 1: Figure S1). This does not rule out the possibility that local myokines production by adipose tissue and leukocytes is increased following overnutrition. Earlier studies reported that highfat diet increases [70] and CR reduces TNFo expression in SM [71], suggesting that CR may circumvent the apoptotic effect of TNF $\alpha$ in SM [72]. Acute early life exposures to TNF $\alpha$ renders muscle cells more susceptible to impaired regeneration when inflammation is encountered in later proliferative life [73], which supports the role TNFa in muscle degeneration. Interestingly, the TNFRSF $12 \mathrm{~A}$ gene was significantly upregulated by WSD and downregulated by CR (Additional file 2: Table S1 and Table 2), while the transcriptional activation of this gene has been previously linked to diffuse muscle atrophy [74].

IL-6: In contrast to TNF $\alpha$, circulating IL-6 levels were increased significantly following CR. Previous studies implicated IL-6 in mediating a proinflammatory response in patients with cancer cachexia $[75,76]$, in women with anorexia nervosa [77] and also in association with aging [78], sarcopenia, and muscle degeneration [79]. Furthermore, we have recently observed that IL-6 levels are significantly elevated in NHPs undergoing androgen deprivation, which was associated with a significant loss of lean mass [35]. These examples outline the involvement of IL-6 in catabolic processes associated with body wasting and cell death. There is evidence that IL-6 secretion from SM is increased after exercise [80, 81]. Furthermore, IL-6 may play a beneficial role as a regulator of glucose homeostasis during exercise. For example, the injection of recombinant IL6 during exercise results in increased glucose infusion and glucose production rates in healthy men [82]. Additionally, IL-6 directly stimulates glucose uptake and fatty acid oxidation in myotubes in vitro [83] and improves glucose tolerance in rodent models (reviewed in [84]. IL-6 is also an important myogenic factor regulating satellite-mediated muscle hypertrophy in response to exercise $[85,86]$.

MIF and PAI-1: Circulating MIF and PAI-1 levels were elevated during WSD and CR, although the significance of these changes remains unclear. MIF has been shown to promote fibroblast survival and collagen synthesis in SM [87-89], while PAI-1 levels are increased after long-term glucocorticoid use, which contributed to muscle wasting and IR in mice [90] and is thought to be responsible for SM fibrosis [91].

\section{Limitations}

The dietary effects on SM transcription need further verification using proteomic, immunological and morphological studies. General anesthesia may influence gene expression in SM, although the relative dietspecific effects are statistically significant. Due to a low sample number, the study is considered to be preliminary and need verification in a larger cohort of animals and in both sexes. For technical reason, the Luminex analysis of circulating cytokines was conducted after 4 months on a WSD and thus are not directly comparable with the RNAseq data.

\section{Conclusions}

WSD induces reprograming of SM transcriptome, with the increased expression of profibrotic and proinflammatory genes and decreased expression of metabolic genes, which persists even after obesity is reversed by CR. This type of programing (metabolic memory) may represent an adaptive mechanism that controls metabolic and structural remodeling of SM, but may also contribute to long-term glucose intolerance and treatment resistance in obese and diabetic patients.

\section{Additional files}

\begin{abstract}
Additional file 1: Figure S1. Luminex analysis of circulating cytokines. Plasma samples were collected while on chow, 4 months on WSD and 4 months after CR, and analyzed in duplicates using Invitrogen Monkey Magnetic 29-Plex Panel, as described in "Materials and Methods". Error bars represent SEM. Statistical significance was determined by repeated-measure one-way ANOVA, ${ }^{*} p<0.05 .{ }^{* *} p<0.01$, ${ }^{* * *} p<0.001$. Abbreviations: FGF, fibroblast growth factor; IL, interleukin; G-CSF, granulocyte-colony stimulating factor; HGF, hepatocyte growth factor; VEGF, vascular endothelial growth factor; INFg, interferon gamma; MDC, macrophage-derived chemokine; I-TAC, interferon-inducible T cell alpha chemokine; RANTES, regulated on activation, normal $T$ cell expressed and secreted; Eotaxin, CCL11; MIF analyte, migration inhibitor factor; TNF-a, tumor necrosis growth factor-alpha; MIP-1a, macrophage inflammatory protein-1alpha; GM-CSF, granulocyte-macrophage colony-stimulating factor; MIP-1b, macrophage inflammatory protein-1 beta; IP-10, interferon-gamma-inducible protein 10; MIG, monokine induced by gamma interferon; MCP-1, monocyte chemotactic protein 1; EGF, epidermal growth factor. (PDF 998 kb)
\end{abstract}

Additional file 2: Table S1. The list of differentially expressed WSD/CHOW genes identified in the present study. Table S2. The list of differentially expressed CR/CHOW genes identified in the present study. Table S3. Erythroid genes identified in the present study. Table S4. qRT-PCR primers used in the study. (XLSX $332 \mathrm{~kb}$ )

\section{Abbreviations}

CR: Caloric restriction; ECM: Extracellular matrix; FFA: Free fatty acid; IR: Insulin resistance; NHP: Nonhuman primate; SM: Skeletal muscle; WSD: Western-style diet

\section{Acknowledgements}

We thank the ONPRC Molecular and Cellular Biology and Primate Genetics Research Support Cores and the ONPRC Obese NHP Resource for outstanding service. We thank Drs. Charles Robert Jr. and Peter Kurre from Oregon Health and Science University for helpful discussion. We thank Christina Nguyen for assistance with preparations of figures and Andrea Rivera for assistance with online data depository. 


\section{Funding}

This work was supported by National Institutes of Health Grants R21 AG047543 (to O.V.), P51 OD011092 for the operation of the Oregon National Primate Research Center, AG043896-01 (to I.M.), and the National Science Foundation Grant ABI-0957099 (to I.M.). These funding sources covered animal and housing costs, labor, experimental procedures, data analysis, computational and publication fees.

\section{Article note}

The original article has been revised: modifications have been made to the titles for Additional File 2, Table S1 and S2. Full information regarding corrections made can be found in the erratum for this article.

\section{Availability of data and materials}

RNAseq data have been deposited into Sequencing Read Archive (SRA), accession number SRP093851, and are available online https:// www.ncbi.nlm.nih.gov/sra/?term=SRP093851.

\section{Authors' contributions}

$\mathrm{IM}$ and KMW helped writing the manuscript and analyzed the data; $\mathrm{MH}$ performed experiments, MR analyzed the data; SS and BSP performed the statistical analysis of RNAseq data; SSF and HW processed RNAseq data; AEW performed experiments; RJ and JLD helped with data analysis and manuscript assembly; OV wrote the manuscript. All authors read and approved the final manuscript.

\section{Competing interests}

The authors declare that they have no competing interests.

\section{Consent for publication}

Not applicable.

\section{Ethics approval and consent to participate}

This study was approved by the ONPRC Institutional Animal Care and Use Committee (IACUC) and conforms to current Office of Laboratory Animal Welfares (OLAW) regulations as stipulated in assurance number A3304-01. The work described in this study has been reviewed by the IACUC including Chemical Safety officer, as well as IBC (Institutional biosafety Committee) who oversees all biological hazardous agents. All animals used in this study were born at and derived from ONPRC (Oregon National Primate Research Center, Oregon Health \& Science University).

\section{Publisher's Note}

Springer Nature remains neutral with regard to jurisdictional claims in published maps and institutional affiliations.

\section{Author details}

'School of Biological Sciences, University of California, Irvine, Irvine, CA 92697, USA. ${ }^{2}$ Division of Cardiometabolic Health, Oregon National Primate Research Center, L584 505 NW 185th Ave., Beaverton, OR 97006, USA. 3Division of Biomedical Sciences, School of Medicine, University of California, Riverside, Riverside, CA 92521, USA. ${ }^{4}$ Department of Public Health and Preventive Medicine, Oregon Health and Science University, Portland, OR 97239, USA. ${ }^{5}$ Division of Neuroscience, Oregon National Primate Research Center, Beaverton, OR 97006, USA. ${ }^{6}$ Department of Neuroscience and Psychiatry, University of Pittsburgh, Pittsburgh, PA 15260, USA. ${ }^{7}$ Department of School of Nursing, Oregon Health and Science University, Portland, OR 97239, USA.

\section{Received: 21 December 2016 Accepted: 16 May 2017}

\section{Published online: 25 May 2017}

\section{References}

1. Kahn SE, Hull RL, Utzschneider KM. Mechanisms linking obesity to insulin resistance and type 2 diabetes. Nature. 2006;444(7121):840-6.

2. Evans JL, Goldfine ID, Maddux BA, Grodsky GM. Are oxidative stressactivated signaling pathways mediators of insulin resistance and betacell dysfunction? Diabetes. 2003;52(1):1-8.

3. Ceriello A. Postprandial hyperglycemia and diabetes complications: is it time to treat? Diabetes. 2005;54(1):1-7.
4. Singleton JR, Smith AG, Russell JW, Feldman EL. Microvascular complications of impaired glucose tolerance. Diabetes. 2003;52(12): 2867-73.

5. Hammes HP, Feng Y, Pfister F, Brownlee M. Diabetic retinopathy: targeting vasoregression. Diabetes. 2011;60(1):9-16.

6. Forbes JM, Coughlan MT, Cooper ME. Oxidative stress as a major culprit in kidney disease in diabetes. Diabetes. 2008;57(6):1446-54.

7. Forbes JM, Cooper ME. Mechanisms of diabetic complications. Physiol Rev. 2013;93(1):137-88.

8. Nitert MD, Dayeh T, Volkov P, Elgzyri T, Hall E, Nilsson E, Yang BT, Lang S, Parikh $\mathrm{H}$, Wessman $\mathrm{Y}$, et al. Impact of an exercise intervention on DNA methylation in skeletal muscle from first-degree relatives of patients with type 2 diabetes. Diabetes. 2012;61(12):3322-32.

9. Reddy MA, Zhang E, Natarajan R. Epigenetic mechanisms in diabetic complications and metabolic memory. Diabetologia. 2015;58(3):443-55.

10. Dahlman I, Sinha I, Gao H, Brodin D, Thorell A, Ryden M, Andersson DP, Henriksson J, Perfilyev A, Ling $C$, et al. The fat cell epigenetic signature in post-obese women is characterized by global hypomethylation and differential DNA methylation of adipogenesis genes. Int J Obes. 2015; 39(6):910-9.

11. Leung A, Trac C, Du J, Natarajan R, Schones DE. Persistent chromatin modifications induced by high fat diet. J Biol Chem. 2016;291:10446-55.

12. Ronn T, Volkov P, Davegardh C, Dayeh T, Hall E, Olsson AH, Nilsson E, Tornberg A, Dekker Nitert M, Eriksson KF, et al. A six months exercise intervention influences the genome-wide DNA methylation pattern in human adipose tissue. PLoS Genet. 2013;9(6):e1003572.

13. Sharples AP, Stewart CE, Seaborne RA. Does skeletal muscle have an 'epi'-memory? The role of epigenetics in nutritional programming, metabolic disease, aging and exercise. Aging Cell. 2016;15:603-16.

14. Jacobsen SC, Brons C, Bork-Jensen J, Ribel-Madsen R, Yang B, Lara E, Hall E, Calvanese V, Nilsson E, Jorgensen SW, et al. Effects of short-term high-fat overfeeding on genome-wide DNA methylation in the skeletal muscle of healthy young men. Diabetologia. 2012;55(12):3341-9.

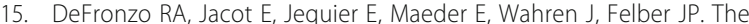
effect of insulin on the disposal of intravenous glucose. Results from indirect calorimetry and hepatic and femoral venous catheterization. Diabetes. 1981;30(12):1000-7.

16. Yu C, Chen Y, Cline GW, Zhang D, Zong H, Wang Y, Bergeron R, Kim JK, Cushman SW, Cooney GJ, et al. Mechanism by which fatty acids inhibit insulin activation of insulin receptor substrate-1 (IRS-1)-associated phosphatidylinositol 3-kinase activity in muscle. J Biol Chem. 2002; 277(52):50230-6.

17. Aguirre V, Werner ED, Giraud J, Lee YH, Shoelson SE, White MF. Phosphorylation of Ser307 in insulin receptor substrate-1 blocks interactions with the insulin receptor and inhibits insulin action. J Biol Chem. 2002;277(2):1531-7.

18. Arkan MC, Hevener AL, Greten FR, Maeda S, Li ZW, Long JM, Wynshaw-Boris A, Poli G, Olefsky J, Karin M. IKK-beta links inflammation to obesity-induced insulin resistance. Nat Med. 2005;11(2):191-8.

19. McNelis JC, Olefsky JM. Macrophages, immunity, and metabolic disease. Immunity. 2014;41(1):36-48.

20. Watts R, McAinch AJ, Dixon JB, O'Brien PE, Cameron-Smith D. Increased Smad signaling and reduced MRF expression in skeletal muscle from obese subjects. Obesity (Silver Spring). 2013;21(3):525-8.

21. Richardson DK, Kashyap S, Bajaj M, Cusi K, Mandarino SJ, Finlayson J, DeFronzo RA, Jenkinson CP, Mandarino LJ. Lipid infusion decreases the expression of nuclear encoded mitochondrial genes and increases the expression of extracellular matrix genes in human skeletal muscle. J Biol Chem. 2005:280(11):10290-7.

22. Berria R, Wang L, Richardson DK, Finlayson J, Belfort R, Pratipanawatr T, De Filippis EA, Kashyap S, Mandarino LJ. Increased collagen content in insulin-resistant skeletal muscle. Am J Physiol Endocrinol Metab. 2006;290(3):E560-5

23. Kang L, Ayala JE, Lee-Young RS, Zhang Z, James FD, Neufer PD, Pozzi A, Zutter MM, Wasserman DH. Diet-induced muscle insulin resistance is associated with extracellular matrix remodeling and interaction with integrin alpha2beta1 in mice. Diabetes. 2011;60(2):416-26.

24. Williams $A S$, Kang $L$, Wasserman $D H$. The extracellular matrix and insulin resistance. Trends Endocrinol Metab. 2015;26(7):357-66.

25. Heilbronn LK, de Jonge L, Frisard MI, DeLany JP, Larson-Meyer DE, Rood J, Nguyen T, Martin CK, Volaufova J, Most MM, et al. Effect of 
6-month calorie restriction on biomarkers of longevity, metabolic adaptation, and oxidative stress in overweight individuals: a randomized controlled trial. JAMA. 2006;295(13):1539-48.

26. Fontana $L$. The scientific basis of caloric restriction leading to longer life. Curr Opin Gastroenterol. 2009;25(2):144-50.

27. Johnson ML, Distelmaier K, Lanza IR, Irving BA, Robinson MM, Konopka AR, Shulman Gl, Nair KS. Mechanism by which caloric restriction improves insulin sensitivity in sedentary obese adults. Diabetes. 2015;65(1):74-84.

28. Colman RJ, Anderson RM, Johnson SC, Kastman EK, Kosmatka KJ, Beasley TM, Allison DB, Cruzen C, Simmons HA, Kemnitz JW, et al. Caloric restriction delays disease onset and mortality in rhesus monkeys. Science. 2009; 325(5937):201-4

29. Mattison JA, Roth GS, Beasley TM, Tilmont EM, Handy AM, Herbert RL, Longo DL, Allison DB, Young JE, Bryant M, et al. Impact of caloric restriction on health and survival in rhesus monkeys from the NIA study. Nature. 2012; 489(7415):318-21.

30. Larson-Meyer DE, Heilbronn LK, Redman LM, Newcomer BR, Frisard M Anton S, Smith SR, Alfonso A, Ravussin E. Effect of calorie restriction with or without exercise on insulin sensitivity, beta-cell function, fat cell size, and ectopic lipid in overweight subjects. Diabetes Care. 2006;29(6):1337-44.

31. Redman LM, Heilbronn LK, Martin CK, Alfonso A, Smith SR, Ravussin E. Effect of calorie restriction with or without exercise on body composition and fat distribution. J Clin Endocrinol Metab. 2007;92(3):865-72.

32. Fontana L, Villareal DT, Weiss EP, Racette SB, Steger-May K, Klein S, Holloszy JO. Calorie restriction or exercise: effects on coronary heart disease risk factors. A randomized, controlled trial. Am J Physiol Endocrinol Metab. 2007; 293(1):E197-202

33. Pound LD, Kievit P, Grove KL. The nonhuman primate as a model for type 2 diabetes. Curr Opin Endocrinol Diabetes Obes. 2014;21(2):89-94.

34. Varlamov O, Chu MP, McGee WK, Cameron JL, O'Rourke RW, Meyer KA, Bishop CV, Stouffer RL, Roberts Jr CT. Ovarian cycle-specific regulation of adipose tissue lipid storage by testosterone in female nonhuman primates. Endocrinology. 2013;154(11):4126-35.

35. Cameron $J \mathrm{~L}$, Jain $\mathrm{R}$, Rais $M$, White $A E$, Beer TM, Kievit $P$, Winters-Stone $K$, Messaoudi I, Varlamov O. Perpetuating effects of androgen deficiency on insulin resistance. Int J Obes. 2016;40(12):1856-63.

36. Papailiou A, Sullivan E, Cameron JL. Behaviors in rhesus monkeys (Macaca mulatta) associated with activity counts measured by accelerometer. Am J Primatol. 2008;70(2):185-90.

37. McGee WK, Bishop CV, Bahar A, Pohl CR, Chang RJ, Marshall JC, Pau FK, Stouffer RL, Cameron JL. Elevated androgens during puberty in female rhesus monkeys lead to increased neuronal drive to the reproductive axis: a possible component of polycystic ovary syndrome. Hum Reprod. 2012;27(2): 531-40.

38. Bergman RN, Ider $\mathrm{YZ}$, Bowden $\mathrm{CR}$, Cobelli C. Quantitative estimation of insulin sensitivity. Am J Physiol. 1979;236(6):E667-77.

39. Edgerton VR, Smith JL, Simpson DR. Muscle fibre type populations of human leg muscles. Histochem J. 1975;7(3):259-66.

40. Koerker DJ, Sweet IR, Baskin DG. Insulin binding to individual rat skeletal muscles. Am J Physiol. 1990;259(4 Pt 1):E517-23.

41. Lillioja S, Young AA, Culter CL, Ivy JL, Abbott WG, Zawadzki JK, Yki-Jarvinen H, Christin L, Secomb TW, Bogardus C. Skeletal muscle capillary density and fiber type are possible determinants of in vivo insulin resistance in man. J Clin Invest. 1987;80(2):415-24

42. Tanner CJ, Barakat HA, Dohm GL, Pories WJ, MacDonald KG, Cunningham PR, Swanson MS, Houmard JA. Muscle fiber type is associated with obesity and weight loss. Am J Physiol Endocrinol Metab. 2002;282(6):E1191-6.

43. Hyatt JP, Nguyen L, Hall AE, Huber AM, Kocan JC, Mattison JA, de Cabo R, LaRocque JR, Talmadge RJ. Muscle-Specific Myosin Heavy Chain Shifts in Response to a Long-Term High Fat/High Sugar Diet and Resveratrol Treatment in Nonhuman Primates. Front Physiol. 2016;7:77.

44. Barr T, Girke T, Sureshchandra S, Nguyen C, Grant K, Messaoudi I. Alcohol Consumption Modulates Host Defense in Rhesus Macaques by Altering Gene Expression in Circulating Leukocytes. J Immunol. 2016;196(1):182-95.

45. Kabanova S, Kleinbongard P, Volkmer J, Andree B, Kelm M, Jax TW. Gene expression analysis of human red blood cells. Int J Med Sci. 2009;6(4):156-9.

46. Barik A, Zhang B, Sohal GS, Xiong WC, Mei L. Crosstalk between Agrin and Wnt signaling pathways in development of vertebrate neuromuscular junction. Dev Neurobiol. 2014;74(8):828-38.

47. Quiat D, Voelker KA, Pei J, Grishin NV, Grange RW, Bassel-Duby R, Olson EN. Concerted regulation of myofiber-specific gene expression and muscle performance by the transcriptional repressor Sox6. Proc Natl Acad Sci U S A. 2011:108(25):10196-201.

48. Ito N, Ruegg UT, Kudo A, Miyagoe-Suzuki Y, Takeda S. Activation of calcium signaling through Trpv1 by nNOS and peroxynitrite as a key trigger of skeletal muscle hypertrophy. Nat Med. 2013;19(1):101-6.

49. Picas L, Viaud J, Schauer K, Vanni S, Hnia K, Fraisier V, Roux A, Bassereau P, Gaits-lacovoni F, Payrastre B, et al. BIN1/M-Amphiphysin2 induces clustering of phosphoinositides to recruit its downstream partner dynamin. Nat Commun. 2014;5:5647.

50. Tagawa M, Ueyama T, Ogata T, Takehara N, Nakajima N, Isodono K, Asada S, Takahashi T, Matsubara H, Oh H. MURC, a muscle-restricted coiled-coil protein, is involved in the regulation of skeletal myogenesis. Am J Physiol Cell Physiol. 2008;295(2):C490-8.

51. Shimoda Y, Matsuo K, Kitamura Y, Ono K, Ueyama T, Matoba S, Yamada H, Wu T, Chen J, Emoto N, et al. Diabetes-Related Ankyrin Repeat Protein (DARP/Ankrd23) Modifies Glucose Homeostasis by Modulating AMPK Activity in Skeletal Muscle. PLoS One. 2015:10(9):e0138624.

52. Hsiao FC, Lin YF, Hsieh PS, Chu NF, Shieh YS, Hsieh CH, Lee CH, Hung YJ. Circulating growth arrest-specific 6 protein is associated with adiposity, systemic inflammation, and insulin resistance among overweight and obese adolescents. J Clin Endocrinol Metab. 2013;98(2):E267-74.

53. Tam CS, Chaudhuri R, Hutchison AT, Samocha-Bonet D, Heilbronn LK. Skeletal muscle extracellular matrix remodeling after short-term overfeeding in healthy humans. Metabolism. 2017;67:26-30.

54. Kang L, Mayes WH, James FD, Bracy DP, Wasserman DH. Matrix metalloproteinase 9 opposes diet-induced muscle insulin resistance in mice. Diabetologia. 2014;57(3):603-13.

55. Nathan DM, Cleary PA, Backlund JY, Genuth SM, Lachin JM, Orchard TJ, Raskin P, Zinman B, Diabetes C, Complications Trial/Epidemiology of Diabetes I. Intensive diabetes treatment and cardiovascular disease in patients with type 1 diabetes. N Engl J Med. 2005;353(25):2643-53.

56. Miao F, Chen Z, Genuth S, Paterson A, Zhang L, Wu X, Li SM, Cleary P, Riggs A, Harlan DM, et al. Evaluating the role of epigenetic histone modifications in the metabolic memory of type 1 diabetes. Diabetes. 2014;63(5):1748-62.

57. Diabetes C, Complications Trial/Epidemiology of Diabetes I, Complications Research G, Lachin JM, White NH, Hainsworth DP, Sun W, Cleary PA, Nathan DM. Effect of intensive diabetes therapy on the progression of diabetic retinopathy in patients with type 1 diabetes: 18 years of follow-up in the DCCT/EDIC. Diabetes. 2015:64(2):631-42

58. Li SL, Reddy MA, Cai Q, Meng L, Yuan H, Lanting L, Natarajan R. Enhanced proatherogenic responses in macrophages and vascular smooth muscle cells derived from diabetic db/db mice. Diabetes. 2006;55(9):2611-9.

59. Villeneuve $L M$, Reddy MA, Lanting LL, Wang M, Meng L, Natarajan R. Epigenetic histone $\mathrm{H} 3$ lysine 9 methylation in metabolic memory and inflammatory phenotype of vascular smooth muscle cells in diabetes. Proc Natl Acad Sci U S A. 2008;105(26):9047-52.

60. Kriketos AD, Pan DA, Sutton JR, Hoh JF, Baur LA, Cooney GJ, Jenkins AB, Storlien LH. Relationships between muscle membrane lipids, fiber type, and enzyme activities in sedentary and exercised rats. Am J Physiol. 1995;269(5 Pt 2):R1154-62.

61. Kriketos AD, Pan DA, Lillioja S, Cooney GJ, Baur LA, Milner MR, Sutton JR, Jenkins AB, Bogardus C, Storlien LH. Interrelationships between muscle morphology, insulin action, and adiposity. Am J Physiol. 1996;270(6 Pt 2):R1332-9.

62. Fink LN, Costford SR, Lee YS, Jensen TE, Bilan PJ, Oberbach A, Bluher M, Olefsky JM, Sams A, Klip A. Pro-inflammatory macrophages increase in skeletal muscle of high fat-fed mice and correlate with metabolic risk markers in humans. Obesity (Silver Spring). 2014;22(3):747-57.

63. Lau SK, Chu PG, Weiss LM. CD163: a specific marker of macrophages in paraffin-embedded tissue samples. Am J Clin Pathol. 2004;122(5):794-801.

64. Kristiansen M, Graversen JH, Jacobsen C, Sonne O, Hoffman HJ, Law SK, Moestrup SK. Identification of the haemoglobin scavenger receptor. Nature. 2001;409(6817):198-201.

65. Sell H, Eckel J, Dietze-Schroeder D. Pathways leading to muscle insulin resistance-the muscle-fat connection. Arch Physiol Biochem. 2006; 112(2):105-13.

66. Varma V, Yao-Borengasser A, Rasouli N, Nolen GT, Phanavanh B, Starks T, Gurley C, Simpson P, McGehee Jr RE, Kern PA, et al. Muscle inflammatory response and insulin resistance: synergistic interaction between macrophages and fatty acids leads to impaired insulin action. Am J Physiol Endocrinol Metab. 2009;296(6):E1300-10. 
67. Hong EG, Ko HJ, Cho YR, Kim HJ, Ma Z, Yu TY, Friedline RH, Kurt-Jones E, Finberg R, Fischer MA, et al. Interleukin-10 prevents diet-induced insulin resistance by attenuating macrophage and cytokine response in skeletal muscle. Diabetes. 2009;58(11):2525-35.

68. Samokhvalov V, Bilan PJ, Schertzer JD, Antonescu CN, Klip A. Palmitate- and lipopolysaccharide-activated macrophages evoke contrasting insulin responses in muscle cells. Am J Physiol Endocrinol Metab. 2009;296(1):E37-46.

69. Kewalramani G, Fink LN, Asadi F, Klip A. Palmitate-activated macrophages confer insulin resistance to muscle cells by a mechanism involving protein kinase C theta and epsilon. PLoS One. 2011;6(10):e26947.

70. Borst SE, Conover CF. High-fat diet induces increased tissue expression of TNF-alpha. Life Sci. 2005;77(17):2156-65.

71. Spaulding CC, Walford RL, Effros RB. Calorie restriction inhibits the agerelated dysregulation of the cytokines TNF-alpha and IL-6 in C3B10RF1 mice. Mech Ageing Dev. 1997;93(1-3):87-94.

72. Phillips T, Leeuwenburgh C. Muscle fiber specific apoptosis and TNF-alpha signaling in sarcopenia are attenuated by life-long calorie restriction. FASEB J. 2005;19(6):668-70.

73. Sharples AP, Polydorou I, Hughes DC, Owens DJ, Hughes TM, Stewart CE. Skeletal muscle cells possess a 'memory' of acute early life TNF-alpha exposure: role of epigenetic adaptation. Biogerontology. 2016;17(3):603-17.

74. Wu CL, Kandarian SC, Jackman RW. Identification of genes that elicit disuse muscle atrophy via the transcription factors p50 and Bcl-3. PLoS One. 2011; 6(1):e16171.

75. Burney BO, Hayes TG, Smiechowska J, Cardwell G, Papusha V, Bhargava P, Konda B, Auchus RJ, Garcia JM. Low testosterone levels and increased inflammatory markers in patients with cancer and relationship with cachexia. J Clin Endocrinol Metab. 2012;97(5):E700-9.

76. Lerner L, Hayes TG, Tao N, Krieger B, Feng B, Wu Z, Nicoletti R, Chiu MI, Gyuris J, Garcia JM. Plasma growth differentiation factor 15 is associated with weight loss and mortality in cancer patients. J Cachex Sarcopenia Muscle. 2015;6(4):317-24

77. Karczewska-Kupczewska M, Adamska A, Nikolajuk A, Otziomek E, Gorska M, Kowalska I, Straczkowski M. Circulating interleukin 6 and soluble forms of its receptors in relation to resting energy expenditure in women with anorexia nervosa. Clin Endocrinol. 2013;79(6):812-6.

78. Ershler WB, Keller ET. Age-associated increased interleukin-6 gene expression, late-life diseases, and frailty. Annu Rev Med. 2000;51:245-70.

79. Berardi E, Annibali D, Cassano M, Crippa S, Sampaolesi M. Molecular and cell-based therapies for muscle degenerations: a road under construction. Front Physiol. 2014;5:119.

80. Ostrowski K, Rohde T, Zacho M, Asp S, Pedersen BK. Evidence that interleukin-6 is produced in human skeletal muscle during prolonged running. J Physiol. 1998;508(Pt 3):949-53.

81. Lauritzen HP, Brandauer J, Schjerling P, Koh HJ, Treebak JT, Hirshman MF, Galbo H, Goodyear LJ. Contraction and AICAR stimulate IL-6 vesicle depletion from skeletal muscle fibers in vivo. Diabetes. 2013;62(9):3081-92.

82. Febbraio MA, Hiscock N, Sacchetti M, Fischer CP, Pedersen BK. Interleukin-6 is a novel factor mediating glucose homeostasis during skeletal muscle contraction. Diabetes. 2004;53(7):1643-8.

83. Carey AL, Steinberg GR, Macaulay SL, Thomas WG, Holmes AG, Ramm G, Prelovsek O, Hohnen-Behrens C, Watt MJ, James DE, et al. Interleukin-6 increases insulin-stimulated glucose disposal in humans and glucose uptake and fatty acid oxidation in vitro via AMP-activated protein kinase. Diabetes. 2006;55(10):2688-97.

84. Pal M, Febbraio MA, Whitham M. From cytokine to myokine: the emerging role of interleukin-6 in metabolic regulation. Immunol Cell Biol. 2014;92(4):331-9.

85. Toth KG, McKay BR, De Lisio M, Little JP, Tarnopolsky MA, Parise G. IL-6 induced STAT3 signalling is associated with the proliferation of human muscle satellite cells following acute muscle damage. PLoS One. 2011;6(3):e17392.

86. Begue G, Douillard A, Galbes O, Rossano B, Vernus B, Candau R, Py G. Early activation of rat skeletal muscle IL-6/STAT1/STAT3 dependent gene expression in resistance exercise linked to hypertrophy. PLoS One. 2013;8(2):e57141.

87. Mitchell RA, Metz CN, Peng T, Bucala R. Sustained mitogen-activated protein kinase (MAPK) and cytoplasmic phospholipase A2 activation by macrophage migration inhibitory factor (MIF). Regulatory role in cell proliferation and glucocorticoid action. J Biol Chem. 1999;274(25):18100-6.

88. Schober A, Bernhagen J, Thiele M, Zeiffer U, Knarren S, Roller M, Bucala R, Weber C. Stabilization of atherosclerotic plaques by blockade of macrophage migration inhibitory factor after vascular injury in apolipoprotein E-deficient mice. Circulation. 2004;109(3):380-5.
89. Taylor JA, Zhu Q, Irwin B, Maghaydah Y, Tsimikas J, Pilbeam C, Leng L, Bucala R, Kuchel GA. Null mutation in macrophage migration inhibitory factor prevents muscle cell loss and fibrosis in partial bladder outlet obstruction. Am J Physiol Renal Physiol. 2006;291(6):F1343-53.

90. Tamura Y, Kawao N, Yano M, Okada K, Okumoto K, Chiba Y, Matsuo O, Kaji $\mathrm{H}$. Role of plasminogen activator inhibitor-1 in glucocorticoid-induced diabetes and osteopenia in mice. Diabetes. 2015;64(6):2194-206.

91. Ardite E, Perdiguero E, Vidal B, Gutarra S, Serrano AL, Munoz-Canoves P. PAI1-regulated miR-21 defines a novel age-associated fibrogenic pathway in muscular dystrophy. J Cell Biol. 2012;196(1):163-75.

92. Varlamov $\mathrm{O}$, White $\mathrm{AE}$, Carroll JM, Bethea $\mathrm{CL}$, Reddy A, Slayden O, O'Rourke RW, Roberts Jr CT. Androgen effects on adipose tissue architecture and function in nonhuman primates. Endocrinology. 2012;153(7):3100-10.

\section{Submit your next manuscript to BioMed Central and we will help you at every step:}

- We accept pre-submission inquiries

- Our selector tool helps you to find the most relevant journal

- We provide round the clock customer support

- Convenient online submission

- Thorough peer review

- Inclusion in PubMed and all major indexing services

- Maximum visibility for your research

Submit your manuscript at www.biomedcentral.com/submit
Biomed Central 